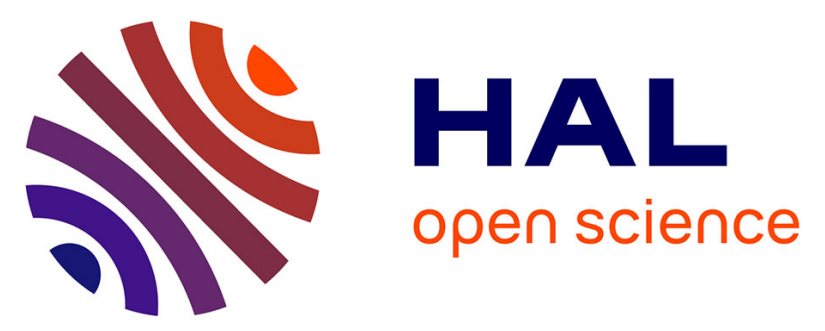

\title{
Role of the hepatic sympathetic nerves in the regulation of net hepatic glucose uptake and the mediation of the portal glucose signal
}

Catherine Di Costanzo, Dominique Dardevet, Doss Neal, Margaret Lautz, Eric Allen, Wanda Snead, Alan Cherrington

\section{To cite this version:}

Catherine Di Costanzo, Dominique Dardevet, Doss Neal, Margaret Lautz, Eric Allen, et al.. Role of the hepatic sympathetic nerves in the regulation of net hepatic glucose uptake and the mediation of the portal glucose signal. AJP - Endocrinology and Metabolism, 2006, 290 (1), pp.E9-E16. 10.1152/ajpendo.00184.2005 . hal-02666554

\section{HAL Id: hal-02666554 https://hal.inrae.fr/hal-02666554}

Submitted on 31 May 2020

HAL is a multi-disciplinary open access archive for the deposit and dissemination of scientific research documents, whether they are published or not. The documents may come from teaching and research institutions in France or abroad, or from public or private research centers.
L'archive ouverte pluridisciplinaire HAL, est destinée au dépôt et à la diffusion de documents scientifiques de niveau recherche, publiés ou non, émanant des établissements d'enseignement et de recherche français ou étrangers, des laboratoires publics ou privés. 
Catherine A. DiCostanzo, Dominique P. Dardevet, Doss W. Neal, Margaret Lautz, Eric Allen, Wanda Snead and Alan D. Cherrington

Am J Physiol Endocrinol Metab 290:9-16, 2006. First published Aug 16, 2005;

doi:10.1152/ajpendo.00184.2005

You might find this additional information useful...

This article cites 49 articles, 20 of which you can access free at:

http://ajpendo.physiology.org/cgi/content/full/290/1/E9\#BIBL

This article has been cited by 2 other HighWire hosted articles:

Intraportal administration of neuropeptide $Y$ and hepatic glucose metabolism

M. Nishizawa, M. Shiota, M. C. Moore, S. M. Gustavson, D. W. Neal and A. D. Cherrington

Am J Physiol Regulatory Integrative Comp Physiol, April 1, 2008; 294 (4): R1197-R1204.

[Abstract] [Full Text] [PDF]

Effects of the nitric oxide donor SIN-1 on net hepatic glucose uptake in the conscious dog Z. An, C. A. DiCostanzo, M. C. Moore, D. S. Edgerton, D. P. Dardevet, D. W. Neal and A. D. Cherrington

Am J Physiol Endocrinol Metab, February 1, 2008; 294 (2): E300-E306.

[Abstract] [Full Text] [PDF]

Updated information and services including high-resolution figures, can be found at:

http://ajpendo.physiology.org/cgi/content/full/290/1/E9

Additional material and information about AJP - Endocrinology and Metabolism can be found at: http://www.the-aps.org/publications/ajpendo

This information is current as of September 2, 2010 .

AJP - Endocrinology and Metabolism publishes results of original studies about endocrine and metabolic systems on any level of organization. It is published 12 times a year (monthly) by the American Physiological Society, 9650 Rockville Pike, Bethesda MD 20814-3991. Copyright @ 2006 by the American Physiological Society. ISSN: 0193-1849, ESSN: 1522-1555. Visit our website at http://www.the-aps.org/. 


\title{
Role of the hepatic sympathetic nerves in the regulation of net hepatic glucose uptake and the mediation of the portal glucose signal
}

\author{
Catherine A. DiCostanzo, Dominique P. Dardevet, Doss W. Neal, \\ Margaret Lautz, Eric Allen, Wanda Snead, and Alan D. Cherrington \\ Department of Molecular Physiology and Biophysics, Vanderbilt University Medical School, Nashville, Tennessee
}

Submitted 28 April 2005; accepted in final form 12 August 2005

DiCostanzo, Catherine A., Dominique P. Dardevet, Doss W. Neal, Margaret Lautz, Eric Allen, Wanda Snead, and Alan D. Cherrington. Role of the hepatic sympathetic nerves in the regulation of net hepatic glucose uptake and the mediation of the portal glucose signal. Am J Physiol Endocrinol Metab 290: E9-E16, 2006. First published August 16, 2005; doi:10.1152/ajpendo.00184.2005.-Portal glucose delivery enhances net hepatic glucose uptake (NHGU) relative to peripheral glucose delivery. We hypothesize that the sympathetic nervous system normally restrains NHGU, and portal glucose delivery relieves the inhibition. Two groups of 42-h-fasted conscious dogs were studied using arteriovenous difference techniques. Denervated dogs (DEN; $n=10$ ) underwent selective sympathetic denervation by cutting the nerves at the celiac nerve bundle near the common hepatic artery; control dogs $(\mathrm{CON} ; n=10)$ underwent a sham procedure. After a 140-min basal period, somatostatin was given along with basal intraportal infusions of insulin and glucagon. Glucose was infused peripherally to double the hepatic glucose load (HGL) for $90 \mathrm{~min}(P 1)$. In $P 2$, glucose was infused intraportally (3-4 $\left.\mathrm{mg} \cdot \mathrm{kg}^{-1} \cdot \mathrm{min}^{-1}\right)$, and the peripheral glucose infusion was reduced to maintain the HGL for $90 \mathrm{~min}$. This was followed by $90 \mathrm{~min}$ (P3) in which portal glucose infusion was terminated and peripheral glucose infusion was increased to maintain the HGL. $P 1$ and $P 3$ were averaged as the peripheral glucose infusion period (PE). The average HGLs $\left(\mathrm{mg} \cdot \mathrm{kg}^{-1} \cdot \mathrm{min}^{-1}\right)$ in CON and DEN were $55 \pm 3$ and $54 \pm 4$ in the peripheral periods and $55 \pm 3$ and $55 \pm 4$ in $P 2$, respectively. The arterial insulin and glucagon levels remained basal in both groups. NHGU $\left(\mathrm{mg} \cdot \mathrm{kg}^{-1} \cdot \mathrm{min}^{-1}\right)$ in CON averaged $1.7 \pm 0.3$ during $\mathrm{PE}$ and increased to $2.9 \pm 0.3$ during $P 2$. NHGU $\left(\mathrm{mg} \cdot \mathrm{kg}^{-1} \cdot \mathrm{min}^{-1}\right)$ was greater in DEN than CON $(P<0.05)$ during PE $(2.9 \pm 0.4)$ and failed to increase significantly $(3.2 \pm 0.2)$ during $P 2$ (not significant vs. CON). Selective sympathetic denervation increased NHGU during hyperglycemia but significantly blunted the response to portal glucose delivery.

autonomic nervous system; liver; canine

POSTPRANDIAL HYPERGLYCEMIA is a concern for individuals with type 2 diabetes. The ability of the liver and peripheral tissues to increase their uptake of glucose after food injestion is therefore an area of interest. There are three major determinants of net hepatic glucose uptake (NHGU): the levels of insulin and glucagon in the blood, the glucose load reaching the liver, and the route of glucose delivery. NHGU increases with an increase in insulin concentration (31) and decreases with an elevation of glucagon (17). Likewise, hepatic glucose uptake is positively correlated with the glucose load. Finally, it has been shown that, when the glucose level is higher in the portal vein than in the hepatic artery, NHGU is augmented (2).

Address for reprint requests and other correspondence: C. DiCostanzo, Dept. of Molecular Physiology and Biophysics, 710 Medical Research Bldg. I (RRB), Vanderbilt Univ. Medical School, Nashville, TN 37232-0615 (e-mail: Catherine.dicostanzo@vanderbilt.edu).
The stimulus for this response has been termed the portal glucose signal. Previous studies carried out in our laboratory have shown that activation of the portal signal not only increases NHGU but also reduces glucose uptake by muscle (2, 18, 33).

In the 1960s, Shimazu et al. $(43,44)$ showed that the autonomic nerves from the hypothalamus control glycogen metabolism. Fluro gold and transsynaptic tracer pseudorabies virus techniques have confirmed the presence of both parasympathetic and sympathetic nerve terminals within the liver, as well as direct connections between hypothalamic centers and the liver $(6,12,23)$. These autonomic nerves innervate the liver along three routes: the portal vein, the hepatic artery, and the bile ducts. Efferent innervation by both parasympathetic and sympathetic nerve fibers has been shown to be responsible for hepatic hemodynamics, bile flow regulation, and control of carbohydrate and lipid metabolism (50). Stimulation of the sympathetic efferents results in an increase in glucose output by the liver through rapid activation of glycogen phosphorylase $(39-41,50)$ as well as an increase in phosphoenolpyruvate carboxykinase (PEPCK) activity. Stimulation of the parasympathetic efferents results in an increase in glycogen synthesis because of activation of glycogen synthase and a decrease or complete inactivation of PEPCK activity (39-42). Afferent signals also emanate from the liver. Afferent fibers constitute $90 \%$ of the fibers in the hepatic vagus nerve (48). They have been shown to convey information regarding plasma glucose (37) and other nutrients as well as to be responsible for osmoregulation, ionoreception, and baroreception (51).

Although extensive research has been carried out relating to hepatic afferents and efferents in the euglycemic and hypoglycemic states $(8,16,21,22,24,26,34)$, less is known about the hyperglycemic state, and it remains unclear how the portal signal may be mediated by these nerves. Total hepatic denervation eliminates the ability of the liver to discriminate between portal and peripheral glucose delivery (3), reinforcing the notion that the response to the portal glucose signal is neurally mediated $(32,36)$. In addition, glucose-sensitive neurons in the portal vein (32) have a discharge rate that is inversely correlated with portal vein glucose concentration. Because stimulation of either the parasympathetic or sympathetic nerves affects glucose metabolism, it is likely that these nerves play a role in mediating the effect of the portal glucose signal.

Several studies have examined the role of the parasympathetic nerves in bringing about the effect of the portal glucose

The costs of publication of this article were defrayed in part by the payment of page charges. The article must therefore be hereby marked "advertisement" in accordance with 18 U.S.C. Section 1734 solely to indicate this fact. 
signal. Stumpel and Jungermann (48) showed in the perfused rat liver that the effect of the portal signal could be abolished by the addition of atropine but mimicked by an infusion of $\mathrm{ACh}$ in the portal vein, leading to the conclusion that the effect was mediated by the parasympathetic nerves. We showed that an adrenergic blockade (portal vein phentolamine and propanolol infusion) and coincident cholinergic stimulation (portal vein $\mathrm{ACh}$ infusion), brought about in the presence of hyperinsulinemic, hyperglycemic conditions, increased NHGU by 1.8 $\mathrm{mg} \cdot \mathrm{kg}^{-1} \cdot \mathrm{min}^{-1}$ when compared with controls (46). These results were inconclusive, however, because portal vein administration of ACh caused an increase in hepatic artery blood flow, leading to a rise in the glucose and insulin loads to the liver. Thus the increase in NHGU was in part load dependent. The possibility also exists that the mediator which increased flow may have also increased NHGU. Because increased hepatic artery flow does not occur in response to portal glucose delivery, this raises a question as to the relevance of the above finding. In line with this, our laboratory has recently shown (7) that cooling the vagus nerves, which interrupts parasympathetic firing (22), had no effect on NHGU in the presence of the portal signal. This suggests that the parasympathetic efferents may not be involved in the transmission of the portal signal.

Our attention has thus turned to the sympathetic nerves and their possible role in mediating the effects of the portal glucose delivery. We hypothesize that the sympathetic nervous system exerts a restraining effect on hepatic glucose uptake that can be reversed by the entry of glucose in the portal vein. We suggest that eliminating the sympathetic nerves using selective hepatic sympathectomy would result in an increase in NHGU in response to peripheral glucose infusion and a reduction in the augmentation of NHGU in response to the portal glucose signal.

\section{RESEARCH DESIGN AND METHODS}

Animals and surgical procedures. Studies were carried out on conscious 42-h-fasted mongrel dogs with a mean weight of $23.1 \pm 0.4$ $\mathrm{kg}$. A fast of this duration was chosen because it produces a metabolic state resembling that in the overnight-fasted human and results in liver glycogen levels in the dog that are at a stable minimum. All animals were maintained on a diet of meat (Kal Kan, Vernon, CA) and chow (Purina Lab Canine Diet No. 5006; Purina Mills, St. Louis, MO) composed of $34 \%$ protein, $14.5 \%$ fat, $46 \%$ carbohydrate, and $5.5 \%$ fiber based on dry weight. The animals were housed in a facility that met American Association for Accreditation of Laboratory Animal Care guidelines, and the protocol was approved by the Vanderbilt University Medical Center Animal Care Committee.

Approximately 16 days before study, each dog underwent a laparotomy under general anesthesia $(0.02 \mathrm{mg} / \mathrm{kg}$ buprenorphine hydrochloride presurgery and $\sim 1 \%$ isoflurane inhalation anesthetic during surgery), and silicone rubber catheters for blood sampling were inserted in the hepatic vein, the portal vein, and a femoral artery as described in detail elsewhere (30). Catheters for hormone infusion were also placed in a splenic and a jejunal vein. Selective sympathetic denervation (DEN, $n=10$ ) or sham denervation (CON, $n=10$ ) occurred at the celiac nerve bundle near the common hepatic artery. The nerve fibers that heavily encased the common hepatic artery were resected from 1-2 cm distal to the origin of the hepatic artery at the celiac trunk to several centimeters past the hepatic branches of the common hepatic artery. The hepatic arterial branches themselves were also skeletonized, and the gastroduodenal artery was stripped of nerves. All nerves surrounding the portal vein and its branches, as well as the vagus nerve, were left intact. Transonic flow probes
(Transonic Systems, Ithaca, NY) were placed around the portal vein and the hepatic artery. The catheters were filled with saline containing heparin (200,000 U/1; Abbott Laboratories, North Chicago, IL), their free ends were knotted, and they, along with the free ends of the Doppler leads, were placed in two separate subcutaneous pockets.

Approximately 2 days before each study, blood was drawn to determine the leukocyte count and the hematocrit for each animal. The dog was studied only if it had a leukocyte count $<18,000 / \mathrm{mm}^{3}$, a hematocrit $>35 \%$, a good appetite (as evidenced by consumption of the entire daily ration), and normal stools.

On the morning of the study, the catheters and Doppler leads were exteriorized from their subcutaneous pockets using local anesthesia (2\% lidocaine; Abbott). The contents of each catheter were aspirated, and the catheters were flushed with saline. The splenic and jejunal catheters were used for intraportal infusion of insulin (Eli Lilly, Indianapolis, IN) and glucagon (Glucagen; Novo Nordisk, Bagsvaerd, Denmark). Angiocaths (Deseret Medical; Becton-Dickinson, Sandy, UT) were inserted in the left cephalic vein for indocyanine green (ICG) infusion (Sigma Immunochemicals, St. Louis, MO), the right cephalic vein for peripheral glucose infusion, and the left saphenous vein for somatostatin (Bachem, Torrance, CA) and $p$-aminohippuric acid (PAH; Sigma) infusions. Each dog was allowed to stand quietly in a Pavlov harness throughout the experiment.

Experimental design. Each experiment consisted of a 100-min equilibration period ( -140 to $-40 \mathrm{~min})$, a 40 -min basal period $(-40$ to $0 \mathrm{~min}$ ), and a $270-\mathrm{min}$ experimental period ( 0 to $270 \mathrm{~min}$ ) that was divided into three 90 -min periods denoted $P 1, P 2$, and $P 3$. In all experiments, a constant infusion of ICG dye $(0.076 \mathrm{mg} / \mathrm{min})$ was initiated at $-140 \mathrm{~min}$. At $0 \mathrm{~min}$, a constant infusion of somatostatin $\left(0.8 \mu \mathrm{g} \cdot \mathrm{kg}^{-1} \cdot \mathrm{min}^{-1}\right)$ was begun to suppress endogenous insulin and glucagon secretion. Glucagon $\left(0.57 \mathrm{ng} \cdot \mathrm{kg}^{-1} \cdot \mathrm{min}^{-1}\right)$ and insulin $(0.3$ $\left.\mathrm{mU} \cdot \mathrm{kg}^{-1} \cdot \mathrm{min}^{-1}\right)$ were then replaced intraportally at basal rates. In addition, a primed continuous peripheral infusion of $50 \%$ dextrose was begun at time $O$ so that the blood glucose could quickly be clamped at the desired hyperglycemic level ( $\sim 235 \mathrm{mg} / \mathrm{dl})$. During $P 1$ [time $(t)=0$ to $t=90$ ], glucose was infused peripherally to double the hepatic glucose load (HGL) in both groups. During $P 2$ ( $t=90$ to $t=180 \mathrm{~min})$, a portal glucose infusion of $20 \%$ dextrose at (3-4 $\mathrm{mg} \cdot \mathrm{kg}^{-1} \cdot \mathrm{min}^{-1}$ ) was initiated to activate the portal signal, and the peripheral glucose infusion was decreased so that the same glucose load to the liver seen in $P 1$ was maintained in $P 2$. During $P 3(t=180$ to $t=270 \mathrm{~min})$, the portal glucose infusion was terminated, and the peripheral glucose infusion was again adjusted to match the HGLs across the three periods. The peripheral glucose infusion rate was adjusted based on the plasma glucose levels and the hepatic blood flow in each individual dog. PAH was added to the portal glucose infusate to assess proper mixing with the blood in the portal and hepatic veins, as previously described (33). $P 1$ and $P 3$ will be referred to as peripheral glucose periods, whereas $P 2$ will be referred to as the portal glucose delivery period.

Femoral artery, portal vein, and hepatic vein blood samples were taken every 20 min during the basal period ( -40 to $0 \mathrm{~min}$ ) and every $15 \mathrm{~min}$ for the last $0.5 \mathrm{~h}$ of each experimental period $(P 1, P 2$, and $P 3)$. The arterial and portal samples were taken simultaneously, and hepatic vein samples were collected $\sim 30$ s later to compensate for transit time of glucose through the liver. Arterial blood samples were also taken every $5 \mathrm{~min}$ from 0 to $270 \mathrm{~min}$ of the experimental period to allow changes to be made in the glucose infusion rate as necessary. The total volume of blood withdrawn did not exceed $20 \%$ of the animal's blood volume, and two volumes of normal saline were infused for each volume of blood withdrawn.

After completion of each experiment, the animal was killed with an overdose of pentobarbital sodium, tissue samples from all seven liver lobes were frozen rapidly with clamps kept in liquid nitrogen, and samples were stored at $-70^{\circ} \mathrm{C}$. This tissue was then used to assess the completeness of the denervation. The norepinephrine content in each liver lobe was measured by HPLC, as previously described (28). 
Processing and analysis of samples. The collection and immediate processing of blood samples have been described previously (15). Four to eight $10-\mu l$ aliquots of plasma from each sample were immediately analyzed for glucose using the glucose oxidase technique in a glucose analyzer (Beckman Instruments, Fullerton, CA). Plasma insulin and glucagon concentrations were determined by RIA, as previously described (33). PAH was also measured in perchloric acid-deproteinized blood, as previously described (33). The methods by which the cortisol, lactate, and glycerol concentrations were measured have also been previously described (33).

Calculations and data analysis. An intraportal infusion of glucose has the possibility of mixing poorly with the blood in the laminar flow of the portal circulation. Thus it was critical to assess the mixing of the portal infusate in $P 2$. This was accomplished by comparing the recovery of $\mathrm{PAH}$ (which was mixed with the portal glucose infusion of D20) in the portal and hepatic veins with the PAH infusion rate using an approach described elsewhere (33). In each group, 13 dogs were studied, and 3 dogs were not included because of poor mixing, as defined previously (29). In the control and denervated animals that were retained, the ratio of PAH recovery in the portal vein to the PAH infusion rate was $1.0 \pm 0.1$ to $1.0 \pm 0.1$, whereas the ratio of $\mathrm{PAH}$ recovery in the hepatic vein to the PAH infusion rate was $0.9 \pm 0.03$ to $1.0 \pm 0.04$, respectively (a ratio of 1.0 would represent perfect mixing). Hepatic blood flow (HBF) was measured using transonic flow probes and by use of ICG according to the method of Leevy et al. (25). The results obtained with transonic flow probes and ICG were not significantly different, but the data reported here were calculated using the transonic-determined flows because their measurement did not require an assumption regarding the distribution of the arterial and portal vein contribution to hepatic blood flow.

An indirect (I) method was used to assess NHGU to minimize the potential errors that arise due to any imperfect mixing of the infused glucose in the blood. Thus HGL was calculated as

$$
\operatorname{load}_{\text {in }}(\mathrm{I})=\left(\mathrm{G}_{\mathrm{A}} \times \mathrm{HBF}\right)+\mathrm{GIR}_{\mathrm{PO}}-\mathrm{GUG}
$$

where $\mathrm{Load}_{\text {in }}$ is the load of glucose entering the liver, $\mathrm{G}_{\mathrm{A}}$ is the arterial blood glucose concentration, GIR $_{\mathrm{PO}}$ is the portal glucose infusion rate, and GUG is the uptake of glucose by the gastrointestinal tract, derived from the data in the peripheral infusion period.

The load of a substrate exiting ( $\left.\operatorname{Load}_{\text {out }}\right)$ the liver was calculated as

$$
\operatorname{load}_{\text {out }}=\left(\mathrm{G}_{\mathrm{H}} \times \mathrm{HBF}\right)
$$

where $\mathrm{G}_{\mathrm{H}}$ represents the hepatic vein glucose concentration.

Net hepatic glucose balance (NHGB) was thus calculated as

$$
\mathrm{NHGB}=\operatorname{load}_{\text {out }}-\operatorname{load}_{\text {in }}(\mathrm{I}) .
$$

Hepatic glucose balance and fractional extraction were also calculated using a direct calculation that has been described previously (38). The results obtained did not differ significantly from those obtained using the indirect calculation. Net fractional substrate extraction by the liver was calculated directly as the ratio of NHGB to Loadin $_{\text {in Nonhepatic }}$ glucose uptake was calculated as previously described (13). The hepatic substrate load and net hepatic balance for lactate and glycerol, hepatic sinusoidal insulin and glucagon concentrations, and net gut glucose uptake were calculated as described previously (38).

For all glucose balance calculations, glucose concentrations were converted from plasma to blood values using previously determined $(18,19)$ conversion factors (the mean of the ratio of the blood value to the plasma concentration). The use of whole blood glucose values ensures accurate hepatic balance measurements regardless of the characteristics of glucose entry in the erythrocyte.

Statistical analysis. All data are presented as means \pm SE. Time course data were analyzed with repeated-measures ANOVA. Independent $t$-tests were used for any comparisons of mean data. Statistical significance was accepted at $P<0.05$.

\section{RESULTS}

Hepatic sympathetic denervation. Liver norepinephrine levels (Table 1) were assessed using HPLC. The average norepinephrine level in the CON group was $658 \pm 68 \mathrm{ng} / \mathrm{g}$ liver, whereas, in the DEN group, it was only $10 \pm 4 \mathrm{ng} / \mathrm{g}$ liver. These values indicate a $>98 \%$ denervation.

Arterial and portal plasma glucose levels. The arterial plasma glucose levels in the control group were $238 \pm 3$, $236 \pm 7$, and $242 \pm 3 \mathrm{mg} / \mathrm{dl}$ during $P 1, P 2$, and $P 3$, respectively, whereas the portal vein plasma glucose levels were $235 \pm 3,255 \pm 8$, and $239 \pm 3 \mathrm{mg} / \mathrm{dl}$, respectively (Fig. 1A). The arterial plasma glucose levels $(236 \pm 3,223 \pm 3,235 \pm$ $2 \mathrm{mg} / \mathrm{dl}$ ) in the DEN group were similar to those seen in the control group, as were the portal vein glucose levels (234 \pm 3 , $243 \pm 4$, and $233 \pm 2 \mathrm{mg} / \mathrm{dl}$ ) during $P 1, P 2$, and $P 3$, respectively (Fig. $1 B$ ).

Arterial plasma and liver sinusoidal insulin and glucagon. Arterial and liver sinusoidal plasma insulin and glucagon levels were maintained at basal values throughout the experiment in both groups (Fig. 2).

Hepatic blood flow and glucose load. Hepatic blood flow $\left(\mathrm{ml} \cdot \mathrm{kg}^{-1} \cdot \mathrm{min}^{-1}\right)$ was similar in all three periods $(P 1, P 2$, and $P 3)$ in CON $(32 \pm 2,30 \pm 2$, and $32 \pm 2)$ and $\operatorname{DEN}(31 \pm 2$, $32 \pm 2$, and $33 \pm 2$ ), respectively (Table 2 ). Because the glucose levels and hepatic blood flows were similar in the two groups, there were no differences in the HGL across time or between treatments (Table 2). The average HGLs $\left(\mathrm{mg} \cdot \mathrm{kg}^{-1} \cdot \mathrm{min}^{-1}\right)$ in the CON and DEN groups were $53 \pm 3$ and $54 \pm 4$ in $P 1,55 \pm 3$ and $55 \pm 4$ in $P 2$, and $57 \pm 3$ and $55 \pm 5$ in $P 3$, respectively. There were no statistical differences in the total glucose infusion rates between the two groups across the three periods. The total glucose infusion rates $\left(\mathrm{mg} \cdot \mathrm{kg}^{-1} \cdot \mathrm{min}^{-1}\right)$ in $P 1, P 2$, and $P 3$ were $3.5 \pm 0.4,4.1 \pm 0.2$, and $4.1 \pm 0.2$ in the CON group, respectively. The total glucose infusion rates in the DEN group were $4.3 \pm 0.4,4.8 \pm$ 0.5 , and $4.6 \pm 0.3$ in $P 1, P 2$, and $P 3$, respectively.

Blood levels and net hepatic balance of lactate and glycerol. Both groups exhibited net lactate uptake in the basal period. Hyperglycemia resulted in a switch to net hepatic lactate output that was similar in both groups and constant over time. The arterial blood lactate levels rose steadily over the three periods in both groups because of net hepatic lactate output (Table 3).

Arterial glycerol levels and net hepatic glycerol uptake fell rapidly in response to hyperglycemia in both groups and

\begin{tabular}{|c|c|c|c|}
\hline \multirow[b]{2}{*}{ Lobe } & \multicolumn{2}{|c|}{ Norepinephrine Content, ng/g liver } & \multirow{2}{*}{$\begin{array}{c}\mathrm{NE} \\
\text { Remaining, \% }\end{array}$} \\
\hline & $\mathrm{CON}$ & DEN & \\
\hline Caudate & $476 \pm 83$ & $2.5 \pm 2.7$ & 0.5 \\
\hline Left central & $524 \pm 126$ & $4.3 \pm 3.8$ & 0.8 \\
\hline Left lateral & $545 \pm 90$ & $3.8 \pm 3.2$ & 0.6 \\
\hline Left posterior & $939 \pm 202$ & $3.8 \pm 2.3$ & 0.4 \\
\hline Quadrate & $582 \pm 82$ & $29.1 \pm 21.4$ & 5.0 \\
\hline Right lateral & $546 \pm 94$ & $27.6 \pm 12.6$ & 5.0 \\
\hline Right central & $716 \pm 149$ & $4.4 \pm 3.6$ & 0.6 \\
\hline
\end{tabular}

Table 1. Hepatic norepinephrine content in each of the seven lobes of 42-h-fasted dogs with innervated or denervated livers

Data are means $\pm \mathrm{SE} ; n=10 \mathrm{dogs}$ in each group. Con, control; DEN, denervated; NE, norepinephrine. 
A

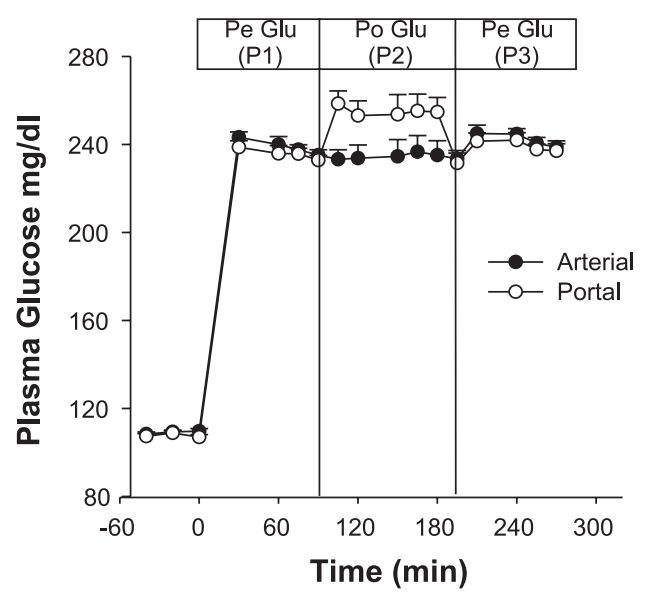

B

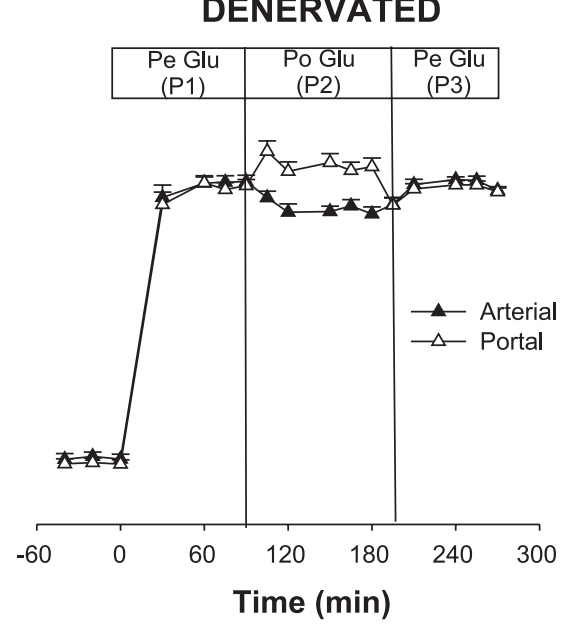

eventually plateaued at an average of $\sim 50 \mu \mathrm{mol} / 1$ and $\sim 1$ $\mu \mathrm{mol} \cdot \mathrm{kg}^{-1} \cdot \min ^{-1}$ (Table 3), respectively (no differences between groups).

NHGB and nonhepatic glucose uptake. Basal net hepatic glucose ouput was not statistically different between the two groups $\left(1.8 \pm 0.3\right.$ and $1.9 \pm 0.2 \mathrm{mg} \cdot \mathrm{kg}^{-1} \cdot \mathrm{min}^{-1}$ in the CON and DEN groups, respectively). Because of the drift that is typically seen in NHGU over time (Table 4), $P 1$ and $P 3$ can be averaged to obtain the mean NHGU response to peripheral hyperglycemia. Thus the average NHGU during peripheral glucose infusion in the CON group was $1.7 \pm 0.3$ $\mathrm{mg} \cdot \mathrm{kg}^{-1} \cdot \mathrm{min}^{-1}$. NHGU in response to peripheral glucose infusion was significantly greater $(P<0.05)$ in the DEN group $\left(2.9 \pm 0.4 \mathrm{mg} \cdot \mathrm{kg}^{-1} \cdot \mathrm{min}^{-1}\right.$; Fig. $\left.3 A\right)$. NHGU significantly increased during $P 2$ (portal glucose infusion) in the CON group, increasing to $2.9 \pm 0.3(\Delta 1.2) \mathrm{mg} \cdot \mathrm{kg}^{-1} \cdot \mathrm{min}^{-1}$, but did not change significantly in the DEN group $[3.2 \pm 0.2(\Delta 0.3)$ $\left.\mathrm{mg} \cdot \mathrm{kg}^{-1} \cdot \mathrm{min}^{-1}\right]$.
Fig. 2. $A$ : arterial plasma insulin. $B$ : arterial plasma glucagon. $C$ : liver sinusoidal insulin. $D$ : liver sinusoidal glucagon levels in 42 -hfasted conscious dogs maintained on a pancreatic clamp during the basal and experimental periods in both the control $(\mathrm{CON})$ and denervated (DEN) groups $(n=10 /$ group). Data are means $\pm \mathrm{SE}$.
A
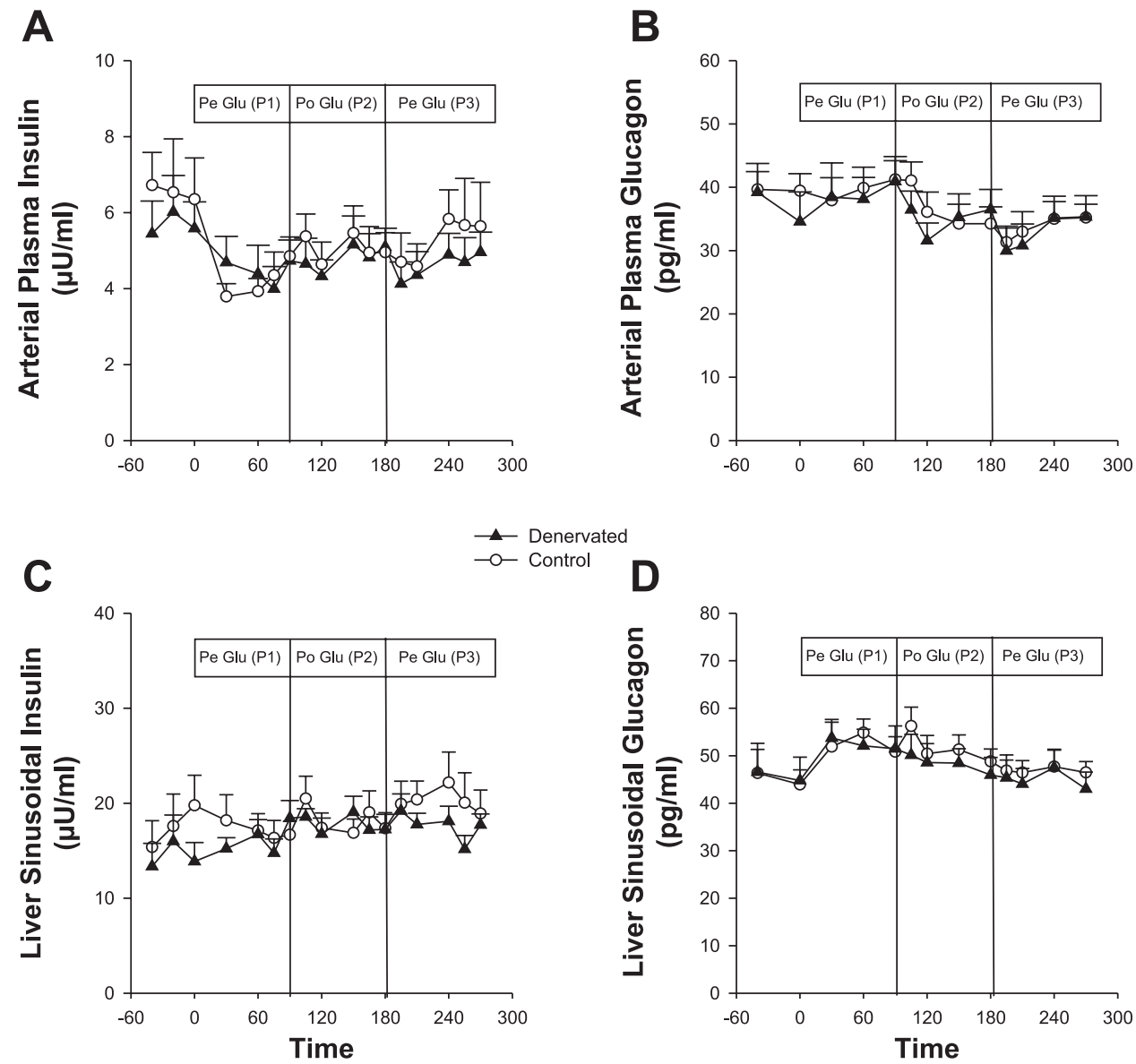
Table 2. Total hepatic blood flow and hepatic glucose load during the experimental periods in 42-h-fasted dogs with innervated or denervated livers

\begin{tabular}{|c|c|c|c|c|c|c|c|c|c|c|c|c|c|c|}
\hline Time, min & \multicolumn{4}{|c|}{ Period 1} & \multicolumn{5}{|c|}{ Period 2} & \multicolumn{5}{|c|}{ Period 3} \\
\hline \multicolumn{15}{|c|}{ Total hepatic blood flow, $\mathrm{ml} \cdot \mathrm{kg}^{-1} \cdot \mathrm{min}^{-1}$} \\
\hline DEN & $31 \pm 2$ & $32 \pm 2$ & $31 \pm 2$ & $31 \pm 2$ & $32 \pm 2$ & $32 \pm 2$ & $32 \pm 3$ & $31 \pm 2$ & $32 \pm 2$ & $33 \pm 2$ & $32 \pm 2$ & $33 \pm 2$ & $34 \pm 2$ & $34 \pm 2$ \\
\hline \multicolumn{15}{|c|}{ Hepatic glucose load (mg/kg/min) } \\
\hline $\mathrm{CON}$ & $52 \pm 3$ & $54 \pm 4$ & $55 \pm 4$ & $55 \pm 5$ & $56 \pm 4$ & $56 \pm 5$ & $54 \pm 4$ & $56 \pm 4$ & $55 \pm 5$ & $52 \pm 5$ & $56 \pm 5$ & $56 \pm 4$ & $55 \pm 5$ & $56 \pm 5$ \\
\hline DEN & $52 \pm 4$ & $54 \pm 4$ & $53 \pm 4$ & $53 \pm 3$ & $56 \pm 3$ & $55 \pm 3$ & $56 \pm 4$ & $55 \pm 3$ & $56 \pm 3$ & $53 \pm 3$ & $55 \pm 3$ & $56 \pm 3$ & $58 \pm 4$ & $58 \pm 3$ \\
\hline
\end{tabular}

Data are means $\pm \mathrm{SE} ; \mathrm{n}=10 \mathrm{dogs}$ in each group.

Net hepatic fractional glucose extraction was 3.1 and $5.4 \%$ in response to peripheral glucose infusion in the $\mathrm{CON}$ and DEN groups, respectively. It increased in response to portal glucose infusion in the CON group (5.4\%; $P<0.05$ ) but failed to increase significantly $(6.5 \%)$ in the DEN group (Table 4$)$.

The average nonhepatic glucose uptake rate seen in response to peripheral glucose infusion was $2.2 \pm 0.1 \mathrm{mg} \cdot \mathrm{kg}^{-1} \cdot \mathrm{min}^{-1}$ in the CON group and $1.6 \pm 0.4 \mathrm{mg} \cdot \mathrm{kg}^{-1} \cdot \mathrm{min}^{-1}$ in the DEN group (Table 4). Nonhepatic glucose uptake decreased significantly $(P<0.05)$ during portal glucose infusion $(P 2)$ in the CON group to $1.2 \pm 0.4(\Delta 1.0) \mathrm{mg} \cdot \mathrm{kg}^{-1} \cdot \mathrm{min}^{-1}$, but it did not change during the same time period in the DEN group [1.6 \pm $0.4(\Delta 0.0) \mathrm{mg} \cdot \mathrm{kg}^{-1} \cdot \mathrm{min}^{-1}$; Fig. $\left.3 B\right]$.

\section{DISCUSSION}

In this study, we tested the hypothesis that a basal inhibitory sympathetic tone to the liver blocks NHGU and that this inhibition is relieved by entry of glucose in the portal vein. Our findings support this concept. There was almost a doubling of NHGU during peripheral glucose infusion in dogs that had undergone selective hepatic sympathectomy compared with those that had not. Furthermore, when the liver was sympathetically denervated, the response to portal glucose delivery was reduced by $\approx 75 \%$. The data regarding nonhepatic glucose uptake are less clear. Although nonhepatic glucose uptake was lower during peripheral glucose infusion in DEN and it did not change in response to portal glucose infusion, the study lacked the statistical power to allow definitive conclusions to be drawn.
Sympathetic nerve fibers reach the liver through the celiac ganglia, celiac plexus, and the splanchnic nerves (18, 19, $39-41)$. The sympathetic fibers form an anterior plexus around the hepatic artery, and Alexander (4) showed that the hepatic artery receives only sympathetic fibers (4). The parasympathetic fibers form a posterior plexus around the portal vein. The postganglionic parasympathetic nerves are derived from ganglia located at the hepatic hilus and within the portal spaces (14). These parasympathetic fibers are separate from any aminergic nerves found in the area $(5,11,27,35,47,49)$. To selectively eliminate sympathetic input to the liver, we removed the nerves associated with the hepatic arterial circulation. The success of the denervation was confirmed by a reduction of norepinephrine in all seven lobes of the liver, which averaged $98 \%$. Neural regeneration and hepatic reinnervation of the dog liver requires $3 \mathrm{mo}(20)$, and thus the denervation was still virtually complete 2 wk postsurgery. It is possible that some vagal innervation may have been compromised during surgery, but given the association of parasympathetic nerves with the portal vein, we believe that most of the parasympathetic fibers remained intact. They were thus still able to exert any regulatory effects that they might have on NHGU and nonhepatic glucose uptake. It should be noted that there were no differences in body weight, food consumption, or basal NHGU between the two groups, suggesting that the chronic decrease in hepatic sympathetic tone did not have any demonstrable baseline effect on the animals. It is important to note that we did not directly measure hepatic sympathetic tone during these experiments but assumed that the level of nor-

Table 3. Arterial blood lactate and glycerol and net hepatic balance of lactate and glycerol during the basal and experimental periods on 42-h-fasted dogs with innervated or denervated livers

\begin{tabular}{|c|c|c|c|c|}
\hline & Basal & $P 1$ & $P 2$ & $P 3$ \\
\hline $\mathrm{CON}$ & $384 \pm 52$ & $845 \pm 104$ & $1,064 \pm 78$ & $1,036 \pm 107$ \\
\hline $\mathrm{CON}$ & $-5.9 \pm 0.8$ & $5.8 \pm 2.4$ & $6.9 \pm 1.5$ & $5.4 \pm 1.6$ \\
\hline DEN & $-7.0 \pm 1.5$ & $8.3 \pm 2.7$ & $7.3 \pm 1.9$ & $7.7 \pm 1.8$ \\
\hline \multicolumn{5}{|c|}{ Arterial blood glycerol, $\mu \mathrm{mol} / \mathrm{l}$} \\
\hline \multicolumn{5}{|c|}{ Net hepatic glycerol uptake, $\mu \mathrm{mol} \cdot \mathrm{kg}^{-1} \cdot \mathrm{min}^{-1}$} \\
\hline $\mathrm{CON}$ & $1.8 \pm 0.2$ & $1.1 \pm 0.2$ & $1.0 \pm 0.2$ & $1.0 \pm 0.2$ \\
\hline DEN & $2.1 \pm 0.3$ & $1.2 \pm 0.2$ & $1.1 \pm 0.2$ & $1.0 \pm 0.2$ \\
\hline
\end{tabular}

Data are means $\pm \mathrm{SE} ; n=10 \mathrm{dogs}$ in each group. $P 1-P 3$, periods $1-3 ;-$, uptake. * Significant statistical difference $(P<0.05)$ from CON. 
Table 4. Net hepatic glucose uptake, net hepatic glucose fractional extraction, and nonhepatic glucose uptake during experimental periods in 42-h-fasted dogs with innervated or denervated livers

\begin{tabular}{llll}
\hline \hline & \multicolumn{1}{c}{$P 1$} & \multicolumn{1}{c}{$P 2$} & \multicolumn{1}{c}{$P 3$} \\
\hline Net hepatic glucose uptake, $\mathrm{mg} \cdot \mathrm{kg}^{-1} \cdot \mathrm{min}^{-1}$ & & & \\
CON & $1.4 \pm 0.4$ & $2.9 \pm 0.3 \dagger$ & $2.0 \pm 0.3$ \\
DEN & $2.5 \pm 0.4^{*}$ & $3.2 \pm 0.2$ & $3.3 \pm 0.5^{*}$ \\
Net hepatic glucose fractional extraction, $\%$ & & & \\
CON & $2.6 \pm 0.6$ & $5.4 \pm 0.4 \dagger$ & $3.6 \pm 0.3$ \\
DEN & $4.9 \pm 0.5^{*}$ & $6.5 \pm 0.7$ & $6.1 \pm 0.5^{*}$ \\
Nonhepatic glucose uptake, $\mathrm{mg} \cdot \mathrm{kg}^{-1} \cdot \mathrm{min}^{-1}$ & & & \\
CON & $2.1 \pm 0.2$ & $1.2 \pm 0.4 \dagger$ & $2.3 \pm 0.2$ \\
DEN & $1.9 \pm 0.2$ & $1.6 \pm 0.4$ & $1.4 \pm 0.5$ \\
\hline
\end{tabular}

Data are means $\pm \mathrm{SE} ; n=10$ dogs in each group. $P<0.05$, significant statistical difference from $\mathrm{CON}\left({ }^{*}\right)$ and from $P 1$ and $P 3(\dagger)$.

epinpehrine in the liver reflected an elimination of sympathetic input to the liver.

Several variables that affect NHGU were minimized to accurately assess the effect of the selective sympathetic denervation on NHGU. Arterial insulin was maintained at a basal level in both groups to avoid the variability seen in the response of NHGU to a rise in insulin. Likewise, the arterial plasma glucagon concentrations were kept constant and basal. The arterial plasma glucose concentration was doubled and clamped across the three periods in both groups. Because there was no change in hepatic blood flow, the HGL to the liver was the same throughout the three experimental periods and was equal in both groups. Thus the differences in NHGU between the two groups cannot be explained by differences in plasma insulin or glucagon levels or the glucose load to the liver.

Prior work in our laboratory has examined the effect of portal glucose delivery on NHGU. In hyperglycemic experiments performed by both Pagliassotti et al. (33) and Hsieh et al. (18) in which both insulin and glucagon were kept basal while plasma glucose was doubled, peripheral glucose delivery resulted in average NHGUs $\left(\mathrm{mg} \cdot \mathrm{kg}^{-1} \cdot \mathrm{min}^{-1}\right)$ of $0.4 \pm 0.3$ and $1.5 \pm 0.3$, respectively. Thus the NHGU of $1.7 \pm 0.3 \mathrm{mg} \cdot \mathrm{kg}^{-1} \cdot \mathrm{min}^{-1}$ that we observed in response to peripheral glucose administration in the control animals of the present study is consistent with previous data. In our earlier studies $(18,33)$, when glucose was given intraportally at $\sim 3.5 \mathrm{mg} \cdot \mathrm{kg}^{-1} \cdot \mathrm{min}^{-1}$ and the HGLs were matched to those seen during peripheral glucose administration,
NHGU $\left(\mathrm{mg} \cdot \mathrm{kg}^{-1} \cdot \mathrm{min}^{-1}\right)$ increased to $2.3 \pm 0.7$ and $3.4 \pm$ 0.5 , respectively. Thus we have shown previously that the portal signal, on the background of hyperglycemia, basal insulin, and basal glucagon, increases NHGU an average of $\sim 1.9$ $\mathrm{mg} \cdot \mathrm{kg}^{-1} \cdot \mathrm{min}^{-1}$. In the present control experiments, the increase in NHGU during portal vs. peripheral glucose delivery was $1.2 \pm 0.2 \mathrm{mg} \cdot \mathrm{kg}^{-1} \cdot \mathrm{min}^{-1}$, in line with the increase we have observed previously.

The dogs with sympathetically denervated livers responded to hyperglycemia quite differently from the normal animals. The average NHGU during the peripheral glucose infusion period was $2.9 \pm 0.4 \mathrm{mg} \cdot \mathrm{kg}^{-1} \cdot \mathrm{min}^{-1}$, a value almost double $(P<0.05)$ that seen under the same conditions in the dogs with innervated livers. With portal glucose delivery, NHGU increased to $3.2 \pm 0.2 \mathrm{mg} \cdot \mathrm{kg}^{-1} \cdot \mathrm{min}^{-1}$ in the DEN group, which is a similar value to that seen in the control animals $(2.9 \pm 0.3$ $\mathrm{mg} \cdot \mathrm{kg}^{-1} \cdot \mathrm{min}^{-1}$ ), yet only $\sim 0.3 \mathrm{mg} \cdot \mathrm{kg}^{-1} \cdot \mathrm{min}^{-1}$ greater than that seen during average peripheral glucose administration. This limited increase is not the result of a saturation of the hepatic response, since these rates of NHGU are significantly lower than rates we have previously shown to occur during portal glucose infusion (45) and lower than the peak rates observed during oral glucose delivery (1). Thus we conclude that the sympathetic efferents play an important role in the regulation of NHGU by exerting a basal inhibitory tone that limits glucose uptake in response to hyperglycemia of peripheral origin. This is consistent with previous work from our laboratory (8), which showed that cooling the vagus nerves (decreasing afferent vagal firing) in the presence of euglycemia and euinsulinemia decreased net hepatic glucose output, presumably by reflexively decreasing the efferent sympathetic outflow to the liver. It is interesting to note that we saw no differences in basal net hepatic glucose output between the two groups in this current study despite hepatic denervation. There are several possible explanations for the discrepancy between our two studies. First, it is possible that vagal cooling results in changes in addition to reduced sympathetic input to the liver. Alternatively, there may be a difference between acute and chronic sympathetcomy.

The question arises as to whether cutting the sympathetic efferents changed NHGU in response to glucose per se (i.e., regardless of the site of delivery) or if, in addition, it blocked the effect of the portal glucose signal. If the response was to glucose per se, then the portal glucose signal should have caused a change of $\sim 1.2 \mathrm{mg} \cdot \mathrm{kg}^{-1} \cdot \mathrm{min}^{-1}$ when glucose was
Fig. 3. Net hepatic glucose uptake $(A)$ and nonhepatic glucose uptake $(B)$ in 42 -h-fasted conscious dogs maintained on a pancreatic clamp during the peripheral and portal glucose infusion periods in both the CON and DEN groups $(n=10 /$ group). Data are means \pm SE. ${ }^{*} P<0.05$ compared with the CON group.
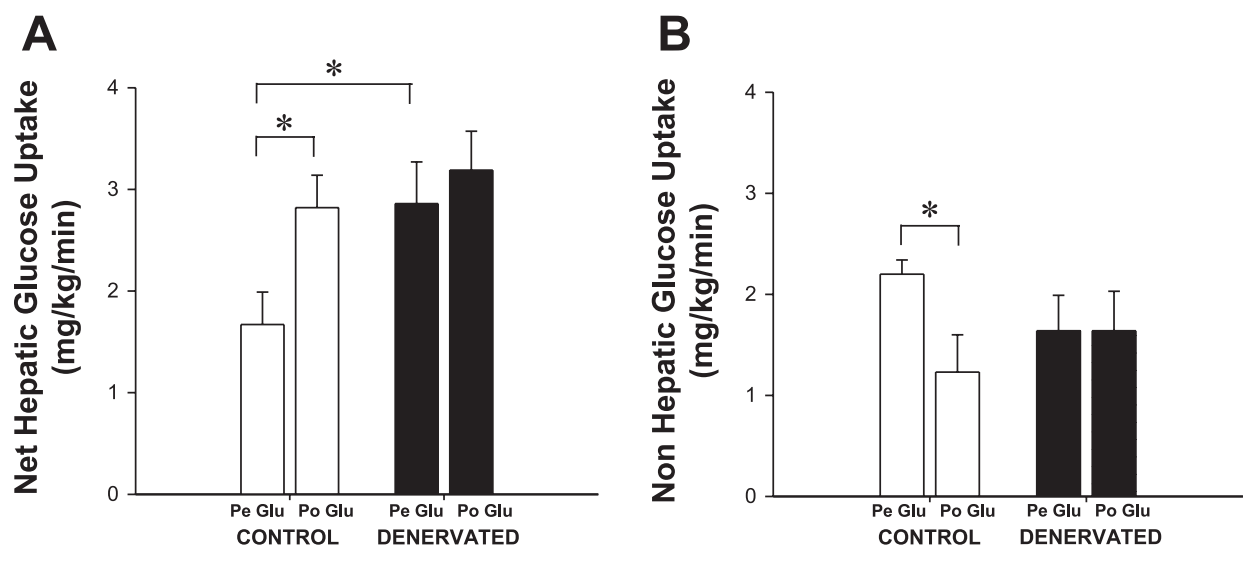

AJP-Endocrinol Metab • VOL 290 JANUARY $2006 \cdot$ www.ajpendo.org 
delivered intraportally in the hepatic denervated dogs. Because the change was only $0.3 \mathrm{mg} \cdot \mathrm{kg}^{-1} \cdot \mathrm{min}^{-1}$, these data suggest that reduced sympathetic tone to the liver is responsible for a significant portion of the increase in NHGU attributed to portal glucose delivery. It must be remembered, however, that we chronically removed sympathetic efferents to the liver. Chronic removal of sympathetic input may result in changes that increase the ability of glucose to increase NHGU, which might not occur in response to the acute removal of sympathetic input associated with portal glucose delivery. It is also possible that sympathetic denervation resulted in a saturation of the response to the portal glucose signal, thus masking any further input (i.e, positive stimuli) generated by portal glucose delivery. Thus, although our data suggest that the portal glucose signal increases NHGU by causing a decrease in sympathetic tone, further proof of this concept is still required.

Based on our data, we cannot draw a definitive conclusion about the additional involvement of a stimulatory signal in the response to portal glucose administration. In the control dogs, the response to portal glucose infusion was $\sim 1.2$ $\mathrm{mg} \cdot \mathrm{kg}^{-1} \cdot \mathrm{min}^{-1}$, whereas in the denervated animals it was $\sim 0.3 \mathrm{mg} \cdot \mathrm{kg}^{-1} \cdot \mathrm{min}^{-1}$. Taken at face value, this suggests that $75 \%$ of the response to portal glucose delivery is caused by removal of an inhibitory tone and $25 \%$ is because of the activation of a stimulatory signal. In the presence of the portal signal, there is an increase in glycogen synthase activation that could act as the stimulatory factor (33). It has also been suggested that the portal signal may cause the translocation of glucokinase, thus also contributing a stimulatory input (9). Unfortunately, the present study lacks the power needed to determine the quantitative contribution of any putative stimulatory signal to the overall response so that equal contribution by inhibitory and stimulatory factors remains possible.

Previous work in our laboratory by Shiota et al. (46) showed that an intraportal infusion of $\alpha$ - and $\beta$-adrenergic receptor antagonists (phentolamine and propanolol, respectively) did not enhance NHGU during hyperinsulinemia and hyperglycemia (achieved via peripheral glucose infusion). This is in apparent conflict with our current findings, but several issues should be noted. Intraportal infusion of the adrenergic blockers would have caused only a partial blockade of sympathetic tone to the liver if the dose of the blockers used was inadequate. Likewise, it is not clear if blockers delivered via the portal vein can reach the synapse and block endogenously released norepinephrine effectively. Additionally, phentolamine has been shown to stimulate postsynaptic $\left(\alpha_{1}\right)$ receptors while inhibiting presynaptic $\left(\alpha_{2}\right)$ receptors, resulting in an enhanced output of norepinephrine (52). It has also been shown that propanolol can have an intrinsic (partial agonist) effect on $\beta$-adrenergic receptors in the liver (10). The partial agonistic properties of these adrenergic antagonists may thus have counteracted any effects attributable to adrenergic blockade. Another way to reconcile our current observations and our previous findings would be to conclude that, in the present study, we removed afferent nerve fibers that travel with the efferent sympathetic nerves. For that to be the case, the afferent fibers would initiate an inhibitory signal to the liver through nonadrenergic mechanisms that would be blocked by sympathetic nerve section. This seems unlikely, since it has been shown that glucosesensitive afferent fibers originating in the liver travel with the vagus nerves.
It has been shown that portal glucose delivery not only leads to an increase in hepatic glucose uptake but also to a decrease in nonhepatic glucose uptake $(2,18,33)$. Under conditions similar to those seen in this experiment, Hsieh et al. $(18,19)$ showed an average nonhepatic glucose uptake of $4.3 \pm 0.5$ $\mathrm{mg} \cdot \mathrm{kg}^{-1} \cdot \mathrm{min}^{-1}$ during peripheral glucose administration, which decreased to $1.0 \pm 0.3 \mathrm{mg} \cdot \mathrm{kg}^{-1} \cdot \mathrm{min}^{-1}$ during portal glucose administration and then returned to $4.6 \pm 0.7$ $\mathrm{mg} \cdot \mathrm{kg}^{-1} \cdot \mathrm{min}^{-1}$ at the termination of the portal glucose signal. In the control animals of the current study, the average nonhepatic glucose uptake during the first peripheral glucose infusion period was $2.1 \pm 0.2 \mathrm{mg} \cdot \mathrm{kg}^{-1} \cdot \mathrm{min}^{-1}$, decreasing significantly to $1.2 \pm 0.4 \mathrm{mg} \cdot \mathrm{kg}^{-1} \cdot \mathrm{min}^{-1}$ with portal glucose delivery. At the termination of the portal glucose administration, nonhepatic glucose uptake returned to $2.3 \pm 0.2$ $\mathrm{mg} \cdot \mathrm{kg}^{-1} \cdot \mathrm{min}^{-1}$. Thus the response to portal glucose delivery in the control animals was consistent with previous data, although the nonhepatic glucose uptake was lower in $P 1$ and $P 3$ than in earlier studies for reasons that are not clear. In the animals with denervated livers, nonhepatic glucose uptake was only slightly less in response to peripheral glucose infusion $\left(1.6 \pm 0.4 \mathrm{mg} \cdot \mathrm{kg}^{-1} \cdot \mathrm{min}^{-1}\right)$ than in the control dogs. There was no change in nonhepatic glucose balance in response to portal glucose infusion in the DEN group. Given the subtle difference noted above, however, one cannot draw a definitive conclusion regarding the role of sympathetic nerves in the mediation of the change in nonhepatic glucose uptake.

In summary, the sympathetic nerves exert an inhibitory tone on liver glucose uptake. Removal of this inhibition by selective hepatic sympathetic denervation leads to an increase in NHGU in response to hyperglycemia induced by peripheral glucose infusion. It also results in a blunting of the increase in NHGU seen in response to intraportal glucose delivery. The portal signal, therefore, leads to the removal of an inhibitory tone to the liver, which in turn allows NHGU to increase. Whether hepatic sympathetic nerves act in concert with an additional stimulatory signal still needs to be determined.

\section{ACKNOWLEDGMENTS}

We appreciate the assistance and support from Mary Courtney Moore, Jon Hastings, and the Diabetes Research and Training Center Hormone Core in these studies. We also thank Phil Williams for technical assistance.

\section{GRANTS}

This work was supported by National Institute of Diabetes and Digestive and Kidney Diseases Grant RO1 DK-43706 and Diabetes Research and Training Center Grant SP-60-Am20593.

\section{REFERENCES}

1. Abumrad NN, Cherrington AD, Williams PE, Lacy WW, and Rabin D. Absorption and disposition of a glucose load in the conscious dog. Am J Physiol Endocrinol Metab 242: E398-E406, 1982.

2. Adkins BA, Myers SR, Hendrick GK, Stevenson RW, Williams PE, and Cherrington AD. Importance of the route of intravenous glucose delivery to hepatic glucose balance in the conscious dog. J Clin Invest 79: 557-565, 1987.

3. Adkins-Marshall BA, Neal DW, Pugh W, Jaspan JB, Cherrington AD, and Adkins-Marshall B. Role of hepatic nerves in response of liver to intraportal glucose delivery in dogs. Diabetes 41: 1308-1319, 1992.

4. Alexander WF. The innervation of the biliary system. J Comp Neurol 72: 357-370, 1940.

5. Amenta F, Cavallotti C, Ferrante F, and Tonelli F. Cholinergic nerves in the human liver. Histochem J 13: 419-424, 1981. 
6. Buijs RM, la Fleur SE, Wortel J, Van Heyningen C, Zuiddam L, Mettenleiter TC, Kalsbeek A, Nagai K, and Niijima A. The suprachiasmatic nucleus balances sympathetic and parasympathetic output to peripheral organs through separate preautonomic neurons. J Comp Neurol 464: 36-48, 2003.

7. Cardin S, Edgerton DS, Farmer B, Neal DW, Lautz M, and Cherrington AD. Vagal cooling and concomitant portal norepinephrine infusion do not reduce net hepatic glucose uptake in conscious dogs. Am J Physiol Endocrinol Metab 286: E226-E233, 2004.

8. Cardin S, Walmsley K, Neal DW, Williams PE, and Cherrington AD. Involvement of the vagus nerves in the regulation of basal hepatic glucose production in conscious dogs. Am J Physiol Endocrinol Metab 283: E958-E964, 2002.

9. Cherrington AD. Banting Lecture 1997. Control of glucose uptake and release by the liver in vivo. Diabetes 48: 1198-1214, 1999.

10. Chu CA, Sindelar DK, Igawa K, Sherck S, Neal DW, Emshwiller M, and Cherrington AD. The direct effects of catecholamines on hepatic glucose production occur via $\alpha_{1}$ - and $\beta_{2}$-receptors in the dog. Am J Physiol Endocrinol Metab 279: E463-E473, 2000.

11. Colle I, Van Vlierberghe H, Troisi R, and De Hemptinne B. Transplanted liver: consequences of denervation for liver functions. Anat Rec A Discov Mol Cell Evol Biol 280A: 924-931, 2004.

12. Delalande JM, Milla PJ, and Burns AJ. Hepatic nervous system development. Anat Rec A Discov Mol Cell Evol Biol 280A: 848-853, 2004.

13. Edgerton DS, Neal DW, Scott M, Bowen L, Wilson W, Hobbs CH, Leach C, Sivakumaran S, Strack TR, and Cherrington AD. Inhalation of insulin (Exubera) is associated with augmented disposal of portally infused glucose in dogs. Diabetes 54: 1164-1170, 2005.

14. Friedman MI. Hepatic nerve function. In: The Liver: Biology and Pathobiology, edited by Arias I, Popper H, Jacoby WB, Schachter D, and Shafritz DA. New York: Raven, 1988, p. 949-959.

15. Galassetti P, Chu CA, Neal DW, Reed GW, Wasserman DH, and Cherrington AD. A negative arterial-portal venous glucose gradient increases net hepatic glucose uptake in euglycemic dogs. Am J Physiol Endocrinol Metab 277: E126-E134, 1999.

16. Hevener AL, Bergman RN, and Donovan CM. Portal vein afferents are critical for the sympathoadrenal response to hypoglycemia. Diabetes 49: $8-12,2000$.

17. Holste LC, Connolly CC, Moore MC, Neal DW, and Cherrington AD. Physiological changes in circulating glucagon alter hepatic glucose disposition during portal glucose delivery. Am J Physiol Endocrinol Metab 273: E488-E496, 1997.

18. Hsieh PS, Moore MC, Neal DW, and Cherrington AD. Hepatic glucose uptake rapidly decreases after removal of the portal signal in conscious dogs. Am J Physiol Endocrinol Metab 275: E987-E992, 1998.

19. Hsieh PS, Moore MC, Neal DW, Emshwiller M, and Cherrington AD. Rapid reversal of the effects of the portal signal under hyperinsulinemic conditions in the conscious dog. Am J Physiol Endocrinol Metab 276: E930-E937, 1999.

20. Ito Y, Takahashi T, Tadokoro F, Hayashi K, Iino Z, Sato K, and Akira K. Regeneration of the hepatic nerves following surgical denervation of the liver in dogs. Liver 18: 20-26, 1998.

21. Jackson PA, Cardin S, Coffey CS, Neal DW, Allen EJ, Penaloza AR, Snead WL, and Cherrington AD. Effect of hepatic denervation on the counterregulatory response to insulin-induced hypoglycemia in the dog. Am J Physiol Endocrinol Metab 279: E1249-E1257, 2000.

22. Jackson PA, Pagliassotti MJ, Shiota M, Neal DW, Cardin S, and Cherrington AD. Effects of vagal blockade on the counterregulatory response to insulin-induced hypoglycemia in the dog. Am J Physiol Endocrinol Metab 273: E1178-E1188, 1997.

23. la Fleur SE, Kalsbeek A, Wortel J, and Buijs RM. Polysynaptic neural pathways between the hypothalamus, including the suprachiasmatic nucleus, and the liver. Brain Res 871: 50-56, 2000.

24. Lamarche L, Yamaguchi N, and Peronnet F. Hepatic denervation reduces adrenal catecholamine secretion during insulin-induced hypoglycemia. Am J Physiol Regul Integr Comp Physiol 268: R50-R57, 1995.

25. Leevy CM, Mendenhall CL, Lesko W, and Howard MM. Estimation of hepatic blood flow with indocyanine green. J Clin Invest 41: 1169-1179, 1962.

26. Matsuhisa M, Yamasaki Y, Shiba Y, Nakahara I, Kuroda A, Tomita T, Iida M, Ikeda M, Kajimoto Y, Kubota M, and Hori M. Important role of the hepatic vagus nerve in glucose uptake and production by the liver. Metabolism 49: 11-16, 2000.
27. Metz W and Forssmann WG. Innervation of the liver in guinea pig and rat. Anat Embryol (Berl) 160: 239-252, 1980.

28. Moghimzadeh E, Nobin A, and Rosengren E. Fluorescence microscopical and chemical characterization of the adrenergic innervation in mammalian liver tissue. Cell Tissue Res 230: 605-613, 1983.

29. Myers SR, Biggers DW, Neal DW, and Cherrington AD. Intraportal glucose delivery enhances the effects of hepatic glucose load on net hepatic glucose uptake in vivo. J Clin Invest 88: 158-167, 1991.

30. Myers SR, Hendrick GK, Williams PE, Triebwasser K, Floyd B, Cherrington AD, and Adkins BA. Importance of the route of intravenous glucose delivery to hepatic glucose balance in the conscious dog. Diabetes 39: 87-95, 1990.

31. Myers SR, McGuinness OP, Neal DW, and Cherrington AD. Intraportal glucose delivery alters the relationship between net hepatic glucose uptake and the insulin concentration. J Clin Invest 88: 158-167, 1991.

32. Niijima A. Glucose-sensitive afferent nerve fibres in the hepatic branch of the vagus nerve in the guinea-pig. J Physiol 332: 315-323, 1982.

33. Pagliassotti MJ, Holste LC, Moore MC, Neal DW, and Cherrington AD. Comparison of the time courses of insulin and the portal signal on hepatic glucose and glycogen metabolism in the conscious dog. J Clin Invest 97: 81-91, 1996.

34. Perseghin G, Regalia E, Battezzati A, Vergani S, Pulvirenti A, Terruzzi I, Baratti D, Bozzetti F, Mazzaferro V, and Luzi L. Regulation of glucose homeostasis in humans with denervated livers. J Clin Invest 100: 931-941, 1997.

35. Reilly FD, McCuskey PA, and McCuskey RS. Intrahepatic distribution of nerves in the rat. Anat Rec 191: 55-67, 1978.

36. Russek M. Current status of the hepatostatic theory of food intake control. Appetite 2: 137-143, 1981.

37. Sakaguchi T and Iwanaga M. Effects of D-glucose anomers on afferent discharge in the hepatic vagus nerve. Experientia 38: 475-476, 1982.

38. Satake S, Moore MC, Igawa K, Converse M, Farmer B, Neal DW, and Cherrington AD. Direct and indirect effects of insulin on glucose uptake and storage by the liver. Diabetes 51: 1663-1671, 2002.

39. Shimazu T. Central nervous system regulation of liver and adipose tissue metabolism. Diabetologia 20: 343-356, 1981.

40. Shimazu T. Neuronal regulation of hepatic glucose metabolism in mammals. Diabetes Metab Rev 3: 185-206, 1987.

41. Shimazu T. Reciprocal innervation of the liver: its significance in metabolic control. Adv Metab Disord 10: 355-384, 1983.

42. Shimazu T and Amakawa A. Regulation of glycogen metabolism in liver by the autonomic nervous system. VI. Possible mechanism of phosphorylase activation by the splanchnic nerve. Biochim Biophys Acta 385: 242-256, 1975.

43. Shimazu T and Fukuda A. Increased activities of glycogenolytic enzymes in liver after splanchnic-nerve stimulation. Science 150: 1607$1608,1965$.

44. Shimazu T, Fukuda A, and Ban T. Reciprocal influences of the ventromedial and lateral hypothalamic nuclei on blood glucose level and liver glycogen content. Nature 210: 1178-1179, 1966.

45. Shiota M, Galassetti P, Monohan M, Neal DW, and Cherrington AD. Small amounts of fructose markedly augment net hepatic glucose uptake in the conscious dog. Diabetes 47: 867-873, 1998.

46. Shiota M, Jackson P, Galassetti P, Scott M, Neal DW, and Cherrington AD. Combined intraportal infusion of acetylcholine and adrenergic blockers augments net hepatic glucose uptake. Am J Physiol Endocrinol Metab 278: E544-E552, 2000.

47. Skaaring $\mathbf{P}$ and Bierring $\mathbf{F}$. On the intrinsic innervation of normal rat liver. Histochemical and scanning electron microscopical studies. Cell Tissue Res 171: 141-155, 1976.

48. Stumpel F and Jungermann K. Sensing by intrahepatic muscarinic nerves of a portal-arterial glucose concentration gradient as a signal for insulin-dependent glucose uptake in the perfused rat liver. FEBS Lett 406: 119-122, 1997.

49. Sutherland SD. An evaluation of cholinesterase techniques in the study of the intrinsic innervation of the liver. J Anat 98: 321-326, 1964.

50. Tiniakos DG, Lee JA, and Burt AD. Innervation of the liver: morphology and function. Liver 16: 151-160, 1996.

51. Uyama N, Geerts A, and Reynaert $\mathbf{H}$. Neural connections between the hypothalamus and the liver. Anat Rec A Discov Mol Cell Evol Biol 280A: $808-820,2004$.

52. Weiner N. Drugs that inhibit adrenergic nerves and block adrenergic receptors. In: The Pharmacological Basis of Therapeutics, edited by Gilman LG and Gilman A. New York: Macmillan, 1980, p. 181-214. 